BULLETIN Bulletin hispanique

HISPANIQUE Université Michel de Montaigne Bordeaux

113-1 | 2011

Actes de 2 colloques

\title{
Transferencias culturales en la prensa y los impresos entre Francia y México en el siglo XIX
}

\section{Lise Andries}

\section{(2) OpenEdition}

\section{Journals}

Edición electrónica

URL: http://journals.openedition.org/bulletinhispanique/1554

DOI: 10.4000/bulletinhispanique.1554

ISSN: 1775-3821

Editor

Presses universitaires de Bordeaux

Edición impresa

Fecha de publicación: 1 junio 2011

Paginación: 457-467

ISBN: 978-2-86781-740-3

ISSN: 0007-4640

Referencia electrónica

Lise Andries, «Transferencias culturales en la prensa y los impresos entre Francia y México en el siglo XIX », Bulletin hispanique [En línea], 113-1 | 2011, Publicado el 01 junio 2014, consultado el 02 mayo

2019. URL : http://journals.openedition.org/bulletinhispanique/1554; DOI : 10.4000/

bulletinhispanique. 1554 


\title{
Transferencias culturales en la prensa y los impresos entre Francia y México en el siglo XIX
}

\author{
LISE ANDRIES \\ CNRS (Paris)
}

Mon propos est d'étudier d'une part de quelle manière s'est construite en France une image du Mexique au XIX'e siècle dans la presse et l'édition, et d'autre part comment les modèles culturels issus de la presse française ont été sélectionnés, transposés et adaptés au Mexique à une époque où cette jeune nation était en quête de références idéologiques et culturelles.

Mi intención es estudiar por una parte cómo se elaboró en Francia una imagen del México de siglo XIX en la prensa y la edición, y por otra parte, cómo los modelos culturales procedentes de la prensa francesa fueron seleccionados, trasladados y adaptados en México en una época en la que esta joven nación estaba en pos de referencias ideológicas y culturales.

This article is focused on two main items : it studies how an image of Mexico was built in the French publications of the nineteenth century, as well as in which ways the cultural patterns stemming from the French press were selected and adapted in Mexico, at a time when the young nation was looking for ideological and cultural references.

Mots-clés : Transferts culturels - Histoire de la presse - France/Mexique - XIX ${ }^{\mathrm{e}}$ siècle.

$\mathrm{V}$

oy a presentar un balance de las investigaciones que se efectuaron durante cuatro años en un grupo francés de nueve miembros, primero en Lyon (laboratoire LIRE CNRS-Université de Lyon 2) luego en

Bulletin Hispanique, Tome 113, n 1 - juin 2011 - p. 457 à 467. 
París (CELLF CNRS-Université de París IV-Sorbonne) sobre «Edición y transferencias culturales en el siglo XIX» en el marco de un proyecto ECOS. Este trabajo se hizo en colaboración con un grupo de investigadores dirigido por Laura Suárez de la Torre en el Instituto Mora de México. El proyecto consistía en estudiar por una parte la imagen de México que se construyó en Francia en el siglo XIX en la prensa y en la edición y por otra parte la manera en que los modelos culturales concebidos dentro de la prensa francesa fueron escogidos, transpuestos y adaptados en la prensa y la edición mexicanas en el siglo XIX. Estos modelos fueron tomados en un sentido amplio porque conciernen también al título de los periódicos, así como la retórica puesta en marcha en los artículos de la prensa, en la literatura y la iconografía. El siglo XIX representa el más apropiado para este estudio porque corresponde a un periodo en el que la joven nación mexicana está en busca de referencias ideológicas y culturales que toma principalmente de la prensa y la edición extranjeras. Estas transferencias culturales no son simples préstamos: revelan todo un trabajo de adaptación a la realidad mexicana, de aculturación y de traducción, cuestiones que constituyeron el tema central de este proyecto.

Este periodo corresponde a un extenso desarrollo de la prensa y la edición en México, una vez que el país logró su independencia en 1821. Corresponde igualmente en Francia a una expansión sin precedentes de la prensa, con la multiplicación de diarios políticos de varias corrientes ideológicas y el surgimiento de los primeros periódicos ilustrados, enciclopédicos o satíricos. Es el momento en el que se asiste a una imbricación estrecha entre el periodismo y la literatura con la aparición de las primeras novelas de folletín, es también el periodo en el que el panorama económico y el campo cultural están cada día más y más asociados. El periódico llega incluso a ser una empresa comercial, como lo demuestra el éxito financiero de Emile de Girardin, verdadero patrón de la prensa que lanzó en 1833 el Musée des Familles, retomado en México bajo el título de El Recreo de las familias, y sobre todo de La Presse en 1836. El mismo año, su competidor y antiguo asociado Dutacq, funda Le Siècle, intitulado en México El Siglo XIX.

Dada la importancia del tema de la afirmación de la identidad nacional, parece oportuno apelar dentro de una lógica de carácter político el marco cronológico mexicano y adoptar la periodización clásica de ese país para la primera etapa de vida nacional (1821-1910) que conduce, del fin de la guerra de liberación colonial y la proclamación de la independencia, al inicio de la revolución de 1910, nueva ruptura radical que determinará a su vez el nuevo orden social y político característico del México contemporáneo.

En esta perspectiva de intercambios con México, la dimensión económica y financiera jugó un papel muy importante y se constituyó en un tema 
prioritario del trabajo del grupo del Instituto Mora. En el grupo francés trabajamos más sobre el contenido de los periódicos y sobre una "poética» del discurso de la prensa. Hemos estudiado los periódicos como objetos literarios que establecieron una tipografía y una estilística específicas, y una temporalidad particular. Pero la colaboración entre los dos grupos de investigación mexicano y francés fue una relación fecunda de complementariedad, reforzada por varios encuentros y misiones entre los dos países.

En la Francia del siglo XIX, la legislación sobre la prensa pasó por largos periodos de represión (Napoleón I y Napoleón III desconfiaban mucho de la prensa y limitaron sus derechos) y raros periodos de liberalización. Los varios regímenes no se atrevieron a tocar al principio de la libertad de prensa, proclamado en la Declaración de los derechos del Hombre en 1789, pero instituyeron impuestos («cautionnement» $\mathrm{y}$ "droit de timbre») que cargaban el presupuesto de los diarios y aumentaban el precio de las suscripciones, impidiendo una difusión popular. A mediados del siglo XIX, la suscripción para un diario ascendía a 60 francos por año, el equivalente de dos semanas de salario para un obrero. La difusión popular de la prensa empezó solamente en 1863 con la creación del Petit Journal que costaba un «sou» (1/20 de franco). En quince años, su difusión alcanzó un tiraje de un millón de ejemplares.

En México, la libertad de prensa estaba teóricamente asegurada desde antes de la obtención formal de la independencia, como una garantía cívica, instituida por la Constitución de Cádiz promulgada en 1812 por los liberales españoles. Se trata de una garantía teórica que, en la práctica, se regirá por una sucesión de leyes contradictorias y de reglamentos restrictivos. Además la creación y la desaparición de los periódicos políticos coincidían en ocasiones con la ideología de los gobiernos que se sucedieron durante la historia agitada de la nación mexicana en el siglo XIX. Unas veces los regímenes prohibieron los periódicos liberales y encarcelaron a sus redactores, otras veces a los conservadores. Por esta razón, la vida de los periódicos estuvo marcada por interrupciones y por reinicios, aún en el caso de los más importantes como El Siglo XIX.

A pesar de estas limitaciones, la prensa jugó un papel importante en el desarrollo de la joven nación mexicana. Para México, el cordón umbilical con la metrópoli había constituido a lo largo de tres siglos de vida colonial un lazo económico, político y cultural esencial, que unió a México con el mundo europeo. A lo largo del siglo XIX, este país -recién constituido en república independiente- inició una búsqueda de referentes susceptibles de guiar su evolución como nación independiente en el viejo continente, la 
apropiación de la modernidad correspondiente a una urgente necesidad de comunicación, de integración política y de unificación cultural.

Uno de nuestros objetos de investigación fue en particular rastrear el papel de Francia y verificar si los referentes culturales franceses fueron determinantes para la construcción de una identidad nacional. En esta época, Francia gozaba de un prestigio político y cultural internacional y París parecía ser la "capital del siglo XIX», para citar el título del libro de Walter Benjamin. Además la nueva nación mexicana dudaba o rechazaba buscar sus modelos políticos y culturales en España, el antiguo poder colonial. No quería buscarlos en Inglaterra, un país cuya religión y lengua parecían demasiado diferentes, y los Estados Unidos se presentaban como una posibilidad o como una amenaza. Alemania, por su parte, no era casi conocida. Entonces era lógico que México volteara su mirada a Francia.

Comparando la evolución de los títulos de los diarios en España, Francia, Inglaterra y México, Alain Vaillant constató que esta evolución siguió las mismas etapas principales en los cuatro países, a pesar de las diferencias geográficas, sociales, políticas: el paso de una prensa de opinión a una prensa de información, el surgimiento en la década 1830 de revistas literarias e ilustradas, de una prensa especializada para los niños, las señoras etc. No sólo los modelos editoriales y tipográficos son casi los mismos, sino que estas evoluciones son simultáneas a través de toda Europa y de un continente a otro. Esta simultaneidad permite suponer la imposición progresiva e ineluctable de modelos trasnacionales. Es preciso constatar también el dinamismo de la prensa mexicana, a pesar de sus tirajes reducidos (un promedio de dos o tres mil para El Monitor republicano). Además se fundaron 31 nuevos periódicos entre 1821 y 1830,50 entre 1830 y 1850 . Los títulos de la prensa mexicana muestran también la búsqueda permanente de unidad nacional y de reforma liberal. Podemos citar, por ejemplo, el Espiritu público, la Voz de la patria, El Fénix de la Libertad. La comparación entre los títulos de los periódicos mexicanos y los europeos muestra que la búsqueda de una identidad cultural se hace igualmente poniendo en valor la naturaleza, los paisajes, y jugando con lo pintoresco mexicano. Pensamos en títulos como El Cuervo mexicano, La Águila mexicana o La Marimba.

Estudiamos la prensa según varias perspectivas: los géneros editoriales (calendarios, diarios, revistas), lostítulos de periódicosysu evolución, la poética periodística en las novelas de folletín y en la página 4 de los diarios, que es la página donde aparecen los anuncios publicitarios. Miguel Rodríguez analizó los calendarios franceses, españoles y mexicanos, y Marie-Laure Aurenche las principales revistas ilustradas francesas, Le Magasin pittoresque, Le Musée des familles, La Mosä̈que, y las correspondientes mexicanas, principalmente 
El Mosaico mexicano y El Museo mexicano ${ }^{1}$. Aunque nos preocupamos a priori por no dar demasiada importancia a Francia, las conclusiones de estas dos investigaciones confirmaron la preeminencia de los modelos franceses. L'Illustration, por ejemplo, se crea en París en 1843, La Ilustración en Madrid en 1849 y La Ilustración mexicana en 1851. Empréstitos y traducciones no significan que las transferencias culturales se llevaron a cabo en un sentido único. El Iris, la revista literaria famosa del italiano Claudio Linati, aparece en México en 1826 (un año después la revista inglesa del mismo título) y en París en 1828. Los modelos periodísticos franceses adaptados en México no pasaban siempre por España. A menudo, la adopción de títulos franceses en la prensa mexicana se efectuaba en el mismo momento que en España o anteriormente. En una época durante la cual hasta la prensa española, para desarrollarse, buscaba modelos europeos, no es sorprendente encontrar traducciones de títulos de la prensa francesa no sólo en México, sino en España ${ }^{2}$.

Las influencias culturales francesas estaban generalmente consideradas como preponderantes en el México del siglo XIX y aceptadas en ese país como signos satisfactorios de «modernidad». Pero con respecto a las revistas ilustradas, es claro que paulatinamente se vuelven más autónomas de sus referentes franceses. En El Mosaico Mexicano, fundado por Isidro Rafael Gondra en 1836, la mayoría de los artículos, al principio, son traducciones de artículos escogidos del Magasin pittoresque. En el calendario de José Mariano Lara que data de la misma época, se ven también grabados europeos de las estaciones y de los trabajos en el campo (las siegas en julio y las vendimias en septiembre) que no se corresponden con la realidad mexicana. Pero en los ańos siguientes, aparecen adaptaciones, así como grabados y textos originales. Ignacio Cumplido, el impresor-editor del Mosaico, sucesor de Isidro Rafael Gondra, y que publica también el gran periódico liberal de Francisco Zarco, El Siglo XIX, explica su proyecto en estos términos: «Nacionalizar el periódico será el principal objeto de nuestras comunes tareas». En particular, la revista acogerá, después de 1840, composiciones de poetas mexicanos porque, según explica Cumplido: «la naturaleza de nuestro suelo [...] es tan fecunda en fenómenos sorprendentes, y tan abundante en paisajes brillantes, que presenta un campo vastísimo a las descripciones pintorescas y al canto

1. Véase también Maria del Carmen Ruiz Castañeda, «El Mosaico Mexicano, o colección de amenidades curiosas e instructivas", Empresa y Cultura en tinta y papel (1800-1860), Laura Suárez de la Torre ed., Instituto de Investigación Dr. José Maria Luis Mora, UNAM, México, 2001, pp.529-535.

2. Véase Jean-François Botrel, Libros, prensa y lectura en la España del Siglo XIX, Madrid, Fundación Germán Sánchez Ruipérez, 1993. 
siempre dulce y armonioso del poeta mexicano.» ${ }^{3}$ Aquí conviene recordar que cuatro años antes, en 1836, se había fundado la Academia de Letrán, primera asociación literaria del México independiente.

Las imágenes muestran, sin lugar a dudas, notables presencias e influencias francesas, como lo muestran las investigaciones de María Esther Pérez Salas $y$, en cierto sentido, Laurence Coudart en el grupo del Instituto Mora. Puede decirse que el paisaje y las costumbres francesas, representadas en los grabados y las litografías, ayudaron a concebir y dibujar las características del imaginario mexicano. Las imágenes litográficas realizadas por Jules David, Lacoste, Rambert o Gérard, así como las obras de artistas viajeros extranjeros, penetraron en el ámbito artístico mexicano y se convirtieron en elementos básicos para desarrollar la litografía en México. En las nuevas revistas literarias -que tomaron sus nombres de las publicaciones francesas de la época y que agregaron el adjetivo de mexicano para señalar su originalidad como El Mosaico Mexicano o El Museo Mexicano- los nombres de Salazar, Iriarte o Blanco, responsables de ornamentar esas publicaciones, pueden citarse como herederos de la tradición francesa y fundadores de una escuela litográfica mexicana. Asimismo, las caricaturas de Honoré Daumier, Gérard Grandville y de Gustave Doré ayudaron a desarrollar, paradójicamente, el espíritu festivo y crítico de los mexicanos.

El estudio del contenido de los periódicos franceses y mexicanos y de sus secciones nos muestra otros procesos de transformación. Sylvain Venayre ha investigado la página 4, la página publicitaria, de los periódicos franceses publicados en México. Esta página ofrece muchos detalles sobre la presencia francesa en la ciudad de México y muestra que la historia de los intercambios entre Francia y México puede apreciarse no solamente a partir de indicadores tales como el número de traducciones o de adaptaciones, o bien las importaciones de impresos franceses sino, también, a través de «bienes culturales» diversos como vinos, la pastelería francesa o las novedades de la moda en el vestido. Durante la segunda mitad del siglo XIX llegaron a publicarse 24 periódicos escritos en francés ${ }^{4}$. El más famoso fue Le Trait

3. El Mosaico Mexicano, t. II, Ignacio Cumplido, «Advertencia preliminar». Sobre Ignacio Cumplido, véase María Esther Pérez Salas, «Ignacio Cumplido: un empresario a cabalidad», Empresa y Cultura en tinta y papel (1800-1860), Laura Suárez de la Torre ed., Instituto de Investigación Dr. José Maria Luis Mora, UNAM, México, 2001, pp.145-156 y «Los secretos de una empresa exitosa: la imprenta de Ignacio Cumplido", Constructores de un cambio cultural: impresores-editores y libreros en la ciudad de México 1830-1855, Laura Suárez de la Torre ed., México, Instituto de Investigación Dr. José María Luis Mora, 2003, pp.101-182.

4. Laurence Coudart, «Periódicos franceses de la ciudad de México: 1837-1911», en Javier Pérez Siller (coord.), México-Francia. Memoria de una sensibilidad común. Siglos XIX-XX, El Colegio de San Luis / CEMCA, México, 1998, p. 103-141 y "Periódicos y periodistas 
d'Union, de René Masson, que pertenecía a la corriente política liberal, y que se publicó de 1849 a 1856 y de 1868 a 1896, es decir un total de 35 años. $\mathrm{El}$ «prospecto» del periódico, publicado el 5 de mayo de 1849, constituye un verdadero proyecto de colaboración entre las dos comunidades, la francesa y la mexicana:

Puisse notre journal servir un jour de trait d'union aux différentes factions de la population française au Mexique; -puisse-t-il également servir de trait d'union entre nos lecteurs et la population mexicaine-; puisse-t-il, de sa faible influence, empêcher à jamais la rupture du trait d'union que la similitude des institutions et des sentiments de bienveillance mutuelle ont si solidement établi entre les deux républiques de l'ancien et du nouveau monde.

(Esperamos que nuestro periódico será en el futuro un vínculo de unión entre los varios grupos de franceses en México, y también un vínculo de unión entre nuestros lectores y la población mexicana; esperamos que, aun siendo débil su influencia, jamás permitirá que se rompa el vínculo de unión que la similitud de instituciones y de sentimientos de mutua benevolencia ha establecido de manera tan sólida entre las dos repúblicas del viejo y del nuevo mundo.)

En nuestro grupo de investigación, Marie-Eve Thérenty ha analizado las novelas de folletín en ambos países. En Francia, el folletín (que apareció por primera vez en La Presse en 1836) jugaba un papel de "contrapunto" dentro del periódico, y creaba un espacio de libertad: Les Mystères de Paris de Eugenio Sue, por ejemplo, que expresaban ideas progresistas y que describían la miseria del pueblo parisiense sin concesiones, se publicaron en el conservador Journal des Débats. Por el contrario, los folletines mexicanos siempre se utilizaron para reforzar la orientación política del periódico. Es interesante constatar que la prensa liberal mexicana, en particular El Siglo XIX y El Monitor Republicano, publicaron casi únicamente novelas de folletín francesas. Sus autores favoritos eran Alexandre Dumas, Lamartine y Eugenio Sue. Por el contrario, la prensa conservadora prefería textos españoles e ingleses; al parecer, para los conservadores, Francia tenía una imagen demasiado revolucionaria y laica. El Universal, un periódico conservador, publicó una obra literaria francesa, Les Martyrs de Chateaubriand. Pero hay que subrayar que era un escritor católico.

De hecho, la recepción mexicana de los hechos culturales franceses - de orden simbólico, ideológico, estético o material- forma un reflejo o un eco,

franceses en México», en La Comunidad francesa en la ciudad de México, Babel-Ciudad de México, n 8, 1999, p. 21-27. 
en constante mutación. Filósofos como Auguste Comte, pensadores políticos como Benjamin Constant, Lammenais y Adolphe Thiers, historiadores como Jules Michelet y literatos como Lamartine, Chateaubriand, Flaubert, Eugène Sue o Alexandre Dumas, padre e hijo, permearon el ambiente mexicano del siglo XIX y ejercieron una gran influencia al ofrecer algunos modelos para pensar y diseńar el pensamiento y la literatura mexicanos. Estos nombres junto con otros más, se convirtieron en autores familiares, a través de sus obras -traducidas al español por editores españoles y mexicanos. Todos ellos constituyeron una fuente de inspiración para los noveles autores mexicanos que asumieron el compromiso de estudiar y describir su propio ser. Con el tiempo, no sólo la traducción, sino que surgieron la apropiación y la adaptación paulatina -verdaderas recreaciones- de una gran variedad de expresiones literarias -comedia, drama, novela popular, novela de folletín. Pero esto no debe hacernos olvidar la importante influencia de las letras españolas en la novela y particularmente en el teatro.

La paradoja y la dificultad del estudio de las transferencias culturales es que son precisamente los préstamos extranjeros los que ayudaron a construir una identidad nacional. El ejemplo del ambiente científico lo muestra bien. De hecho existieron vínculos entre los medios científicos franceses y mexicanos que jugaron un papel menos visible que la prensa en la circulación de los referentes culturales, pero su impacto fue duradero y profundo. En el grupo de investigación francés, Joëlle Chassin trabajó sobre Les Nouvelles Annales de géographie, la revista de la Sociedad francesa de geografía que TernauxCompans dirigió en los años 1840. Ternaux-Compans conocía América latina y había comprado la biblioteca de Muñoz, el historiógrafo del rey de España a finales del siglo XVIII, una biblioteca llena de documentos sobre la conquista de América y sobre México. Publicó una parte de estos documentos en Les Nouvelles Annales, divulgando así entre el público letrado francés la historia de México, de la misma manera que dando a conocer las actas e informes sobre las reuniones de la Sociedad de Geografía mexicana que se fundó en 1833 -lo que supone vínculos entre las elites intelectuales de Francia y México. Claire Fredj ha mostrado, por su parte que, a pesar de la ocupación del país por el ejército francés entre 1862 y 1867, los médicos militares franceses y los médicos mexicanos escribieron juntos en las revistas médicas mexicanas y trabajaron en la «Comisión científica, literaria y artística de México», jorganizada por el general Bazaine!

Los intercambios y la colaboración entre algunos intelectuales mexicanos y franceses durante la Intervención francesa podrían parecer una traición del ideal nacionalista, pero coinciden precisamente con la política voluntarista mexicana de integración dentro del "concierto de las naciones» occidentales 
que empezó después de la Independencia. Según Jean-François Botrel, Francia exportó tres veces más impresos a España y América ibérica que los que importó, durante la segunda mitad del siglo. Una parte de éstos eran libros en lengua francesa. En particular, existía una literatura científica, médica y técnica en francés que no podía publicarse en español por falta de público suficiente y que ayudó a formar a las elites técnicas y médicas de América ${ }^{5}$. Durante todo ese siglo, la construcción de la nueva nación y su organización -siguiendo a los países más civilizados y más progresistaspermitió la formación y el reconocimiento internacional de una comunidad científica mexicana.

La cuestión que nos interesaba también era conocer cómo los dos pueblos se veían mutuamente y qué imágenes habían elaborado el uno del otro. El estudio comparativo de las prensas mexicana y francesa durante los ańos 1850-1860 que he hecho muestra que periódicos como El Siglo XIX daban casi todos los días informaciones sobre la vida literaria, científica y política de Francia, mientras que en contraste los periódicos franceses publicaban esporádicamente notas e imágenes sobre México. En los principales diarios liberales, Le Siècle y La Presse, y en los diarios conservadores como Le Constitutionnel, estas informaciones concernían menos la cultura o la sociedad mexicana que la situación política y diplomática, la guerra de Texas o las guerras civiles. Pero es verdad también que los periódicos franceses en general hablaban más de México que de los otros países de América ibérica.

Otros vínculos importantes de México con Francia, que se deben señalar, procedían de los relatos de viajeros como Mathieu de Fossey, Jacques Arago o Lucien Biar que circularon en Francia en esta época. Se difundieron también en la segunda mitad del siglo las novelas de Gabriel Ferry, Costal l'Indien o Scènes de la vie mexicaine, y obras de Gustave Aimard que Arthur Rimbaud leyó y apreció. Estas obras sedujeron a más de un lector atraído por la exuberancia y el exotismo de México. Aunque el público francés conocía mal México. Es probable que para los lectores franceses, las novelas sobre México y los relatos de viajeros se mezclaran entre sí. En estas obras, la descripción de México corresponde a un sueńo sobre el Nuevo Mundo, una tierra de grandes espacios vírgenes que llama al espíritu de conquista, de colonización y de empresa ${ }^{6}$.

5. Jean-François Botrel, «L'exportation des livres et modèles éditoriaux français en Espagne et en Amérique latine (1814-1914)», Les mutations du livre et de l'édition dans le monde, du XVIII siècle à l'an 2000, Jacques Michon et Jean-Yves Mollier éd., París, L’Harmattan, 2001, pp. 219-239.

6. Gabriel Ferry, cuyo verdadero nombre era Louis de Bellemare, vivió en México de 1831 a 1837. Ver Sylvain Venayre, La Gloire de l'aventure. Genèse d'une mystique moderne 18501940, París, Aubier, 2002. 
¿En la prensa mexicana del siglo XIX, qué imagen de Francia se construyó? En primer lugar, Francia era considerada como el país de la Ilustración, de la Revolución de 1789 y de los derechos del hombre. París era el centro de la moda, de las artes y de la literatura. Pero Francia pertenecía también al antiguo mundo, es decir a un mundo decadente. Este último tema se desarrolla particularmente en la prensa liberal mexicana en el momento de la Intervención. Prensa que era muy francófila y no entendió la decisión de Napoleón III de invadir México (la prensa liberal francesa tampoco). Los diarios liberales expresan un discurso contradictorio en el cual se mezclan ira y amor decepcionado. Leemos por ejemplo en El Siglo XIX del 6 de Noviembre 1862:

Francia es tal vez la nación más querida en América. Tienen con los franceses similitud de idioma, de religión, de usos y de costumbres; estudian sus publicistas e historiadores. Se empapan en su literatura. [...] Educados esos pueblos en los principios del 89, aman a la Francia que les ayudó con sus ideas a nacer a la vida de hombres y pueblos libres. Pero la guerra de México [...] empieza a cambiar en odio ese amor, y en hostilidad aquel entusiasmo.

El proceso de aculturación de lo escrito, la apropiación de palabras y de imágenes implicó la presencia necesaria de otros actores y factores, responsables de hacer llegar los impresos a las elites del país. La formación de redes culturales y comerciales fue una característica de los nuevos tiempos, en donde los libreros y editores extranjeros y mexicanos favorecieron la llegada y circulación de novedades editoriales -libros, revistas, almanaques, folletos, periódicos, manuales escolares, novelas, etc.- que fueron recibidas y aprovechadas por los intelectuales mexicanos en la concepción y desarrollo de una cultura nacional. Laura Suárez de la Torre habla de ello y muestra en su artículo del presente volumen ${ }^{7}$ la importancia de los libreros extranjeros en México ${ }^{8}$. En París también existían librerías especializadas en el comercio con América latina e impresores publicando revistas en español para los lectores americanos que querían recibir las informaciones directamente de la capital francesa. Citaremos el Almanaque Universal Hispanoamericano, un

7. Véase Laura Suárez de la Torre, "Construir un mercado, renovar las lecturas y hacer nuevos lectores. La Librería de Frédéric Rosa (1824-1850) ", Bulletin Hispanique, 113, $n^{\circ} 1-2011$ - p. 469 à 483.

8. Véase Laura Suárez de la Torre, "L’imprimé au cœur de la construction savante de l'identité», Archéologie du sentiment en Amérique latine, Denis Rolland éd., París, L'Harmattan, 2005. 
calendario dirigido por José Segundo Flórez, una revista como el Eco de Ambos Mundos y, sobre todo, el Correo de Ultramar.

Se necesitaría hacer una investigación en particular sobre el Correo de Ultramar, para saber quiénes escribían en él, quiénes lo leían. El Correo de Ultramar «Periódico político, literario, mercantil e industrial» se publicó por Lassalle y Melan, de 1842 à 1886. Lassalle y Melan publicaron también un Museo ilustrado, una Parte Literaria Ilustrada del Correo de Ultramar y regalaba dos veces al mes La Moda del Correo de Ultramar, una revista ilustrada, para los suscriptores. En el número de enero 1869, se puede leer por ejemplo: «El primer baile de las Tullerías ha tenido lugar en la noche de lunes. El magnífico salón del Trono resplandecía de beldades de las representaciones de muchos países del mundo. El lujo era como siempre extraordinario.» Ciertamente el público del Correo de Ultramar no era un público popular, pero permitía a las élites sociales americanas vivir a distancia la vida elegante y sofisticada de la Corte Imperial, así como descubrir las últimas modas parisinas.

En conclusión, esta cadena de intermediarios culturales favoreció el conocimiento de las distintas manifestaciones de la cultura francesa, en el ambiente mexicano decimonónico que mostraba una apertura hacia las distintas expresiones y representaciones ideológicas y plásticas provenientes del exterior. De esta manera, la literatura, la historia, el arte, la moda, la ciencia, la técnica mexicanas, poco a poco definieron sus representaciones, a partir de un lento proceso de elaboración en donde los modelos extranjeros ejercieron una gran influencia. La prensa francesa, en particular, jugó un papel muy importante en la difusión de los modelos franceses, en la construcción progresiva del espacio público nacional, y finalmente en la internacionalización y uniformización de las costumbres y pensamientos entre Europa y el Nuevo Mundo. Pero no ha de olvidarse que este fenómeno sólo tocó a las clases superiores de la sociedad y que el pueblo y su cultura tradicional se mantuvieron al margen de estos intercambios.

Francia y México establecieron vínculos especiales durante todo el siglo XIX, vínculos sin duda muy estrechos que Francia no llegó a tener con otros países de América latina. La Intervención militar francesa no puso realmente estos vínculos en peligro, como lo prueba el conocido afrancesamiento posterior del régimen porfiriano. México también fue uno de los países de América latina que más fascinó y atrajo a los franceses, como lo muestra la importancia de la comunidad francesa establecida en México, durante el siglo XIX. En esta antigua y estrecha relación, se ha querido inspirar nuestro grupo de investigadores, para continuarla en estos inicios del siglo XXI, como un reto a la cooperación intelectual. 